\title{
Do we need a protocol for weaning patients from noninvasive ventilation?
}

\author{
Gopi C. Khilnani, Neetu Jain
}

Positive pressure ventilation had improved outcomes in critically ill patients over last several decades. Each day on mechanical ventilation (MV) leads to several complications including ventilator associated pneumonia, which has significant attributable mortality. ${ }^{[1]}$ Prior to 1994, several modes of weaning were used for liberation from invasive MV. The landmark study by Brochard et al. in 1994, inferred that pressure support ventilation (PSV) was the best mode of weaning; however, subsequent study by Esteban et al. in 1995 concluded that spontaneous breathing trial (SBT) was superior to PSV. ${ }^{[2,3]}$ Subsequently, the same author with a well-designed randomized controlled trial (RCT) concluded that half an hour SBT was as good as $2 \mathrm{~h}$ SBT for weaning from MV ${ }^{[4]}$ Both the studies led to the conclusion that synchronized intermittent mandatory ventilation was inferior mode of weaning that was routinely used prior to these studies and SBT or PSV are established as preferred modes. Therefore, there are well defined parameters and indices to liberate patients from MV. This has led to shorter duration of invasive MV and better outcomes.

Noninvasive positive pressure ventilation (NIV) has been used to obviate the requirement of endotracheal intubation. There have been several RCTs for utility of this modality in acute exacerbation of chronic obstructive pulmonary disease (COPD) and it has been beyond doubt that it reduces the requirement of endotracheal intubation, Intensive Care Unit (ICU) stay, cost of care and mortality. ${ }^{[5-7]}$ NIV is also useful for patients with acute cardiogenic pulmonary edema, neuromuscular weakness due to several causes; however, its use in acute hypoxemic respiratory failure is still under

From:

Department of Pulmonary Medicine and Sleep Disorders, All India Institute of Medical Sciences, New Delhi, India

\section{Correspondence:}

Prof. Gopi C. Khilnani, Department of Pulmonary Medicine and Sleep Disorders, All India Institute of Medical Sciences, New Delhi - 110 029, India. E-mail: gckhil@gmail.com

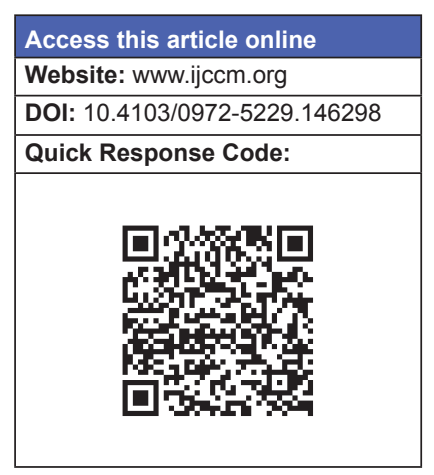

investigation. ${ }^{[8]}$ There are well-defined indications for putting patient on NIV; however, weaning from NIV is carried out depending upon the individual choice of the intensivists. Unlike invasive MV, there are no guidelines for weaning patients from NIV. One of the reasons could be that unlike endotracheal intubation, it is easy to remove the patient from NIV and then reinstate the same several times a day without causing any harm to patients. Understandably, there is a tendency to prolong the duration of NIV fearing complication from withdrawal of ventilation. It can be reasonably deduced that a significant number of patients might be receiving NIV for a longer time than necessary. Akin to invasive $\mathrm{MV}$ it is desirable to minimize the duration of ventilator support with NIV as well to reduce the complications of NIV itself and other hospital acquired complications due to prolonged hospital stay. There are several parameters that need to be considered while withdrawing positive pressure ventilation in patients recovering from acute exacerbation of COPD, which is the main indication for this mode of ventilation. The patients with acute exacerbation of COPD generally have moderately severe airway obstruction and their arterial blood gases even before the exacerbation are subnormal. It has been seen that even after withdrawal of positive pressure ventilation the partial pressure of carbon dioxide remains more than normal, and $\mathrm{PaO}_{2}$ is also subnormal despite patient not requiring NIV. Therefore, the parameters for weaning from NIV in 
patient with COPD have to be different from other conditions such as acute respiratory distress syndrome, which require MV. There are a very few studies which have addressed the issue of protocols of weaning from NIV and all these studies indeed have a small sample size hence, are largely inconclusive. A RCT published by Lun et al. did not show any benefit of stepwise NIV withdrawal versus immediate withdrawal in patients with COPD recovering from hypercapnic respiratory failure. In this study, $74.3 \%$ patients were successfully weaned off with a stepwise approach as compared $56 \%$ in immediate withdrawal group $(P<0.139)$. Although the percentage looks very impressive, the study results were statistically insignificant. The authors themselves commented that a larger sample size would have led to a better inference. As would be expected from a small sample size, there was no difference in mortality between the two groups. ${ }^{[9]}$

It has been observed that physicians often used their clinical judgment to wean the patient from NIV using various parameters such as clinical improvement, heart rate, respiratory rate, level of consciousness and blood gas analysis. In literature, there are no protocol outlines which are evidence based. To investigate this issue Duan et al. conducted RCT comparing protocol directed versus physician directed weaning in patients using NIV for any cause of respiratory failure. Majority of these patients were with exacerbation of COPD. The authors concluded that the protocol directed weaning decreased the duration of NIV and ICU stay. This small but a landmark study brings out very important issue of protocolized weaning in patients on NIV, which should have a set pattern in order to improve the outcome of the patients including reduced ICU stay. ${ }^{[10]}$

Damas et al. studied a protocol based on progressive periods of NIV withdrawal in 78 patients with acute exacerbation of COPD. Weaning was considered in patients within $24 \mathrm{~h}$ without acidosis and respiratory rate $<25 / \mathrm{min}$. Weaning was performed as follows: During the first $24 \mathrm{~h}$ in each $3 \mathrm{~h}, 1 \mathrm{~h}$ without NIV (except during night period), in the $2^{\text {nd }}$ day in each $3 \mathrm{~h}, 2 \mathrm{~h}$ without NIV (except during night period) and in the $3^{\text {rd }}$ day NIV was used only during the night period. It was found that all patients completed the weaning protocol with no re-institution of NIV during hospitalization. ${ }^{[11]}$

In conclusion, there is marked heterogeneity in the weaning strategies used in previous studies that aimed at studying the utility of NIV in acute respiratory failure. The Royal College of Physicians and the British Thoracic
Society published guidelines in 2008 on the use of NIV in the management of patients with COPD and suggested a 4-day weaning strategy, starting with reduction of NIV use during daytime. The suggested protocol is as follows: ${ }^{[12]}$

- Continue NIV for $16 \mathrm{~h}$ on day 1

- Continue NIV for $12 \mathrm{~h}$ on day 2 including 6-8 h overnight use

- Discontinue NIV on day 3, unless continuation is clinically indicated.

This protocol, however, is not a guideline and not followed universally. Lack of evidence-based protocol for weaning from NIV may lead to prolonged length of hospital stay, increase in ICU related infections and cost of care. It is quite possible that in the absence of a weaning protocol patients are kept on NIV longer than necessary. At the same time, it is also likely that too rapid withdrawal may lead to deterioration in clinical condition and increase incidence of intubation that can result in an adverse outcome. It can also be agreed that an evidence-based protocol for weaning from NIV is the need of the hour that would shorten the length of hospital/ICU stay and improve outcome parameters.

\section{References}

1. Rello J, Ollendorf DA, Oster G, Vera-Llonch M, Bellm L, Redman R, et al. Epidemiology and outcomes of ventilator-associated pneumonia in a large US database. Chest 2002;122:2115-21.

2. Esteban A, Frutos F, Tobin MJ, Alía I, Solsona JF, Valverdú I, et al A comparison of four methods of weaning patients from mechanical ventilation. Spanish Lung Failure Collaborative Group. N Engl J Med 1995;332:345-50.

3. Brochard L, Rauss A, Benito S, Conti G, Mancebo J, Rekik N, et al. Comparison of three methods of gradual withdrawal from ventilatory support during weaning from mechanical ventilation. Am J Respir Crit Care Med 1994;150:896-903.

4. Esteban A, Alía I, Tobin MJ, Gil A, Gordo F, Vallverdú I, et al. Effect of spontaneous breathing trial duration on outcome of attempts to discontinue mechanical ventilation. Spanish Lung Failure Collaborative Group. Am J Respir Crit Care Med 1999;159:512-8.

5. Girou E, Schortgen F, Delclaux C, Brun-Buisson C, Blot F, Lefort Y, et al. Association of noninvasive ventilation with nosocomial infections and survival in critically ill patients. JAMA 2000;284:2361-7.

6. Khilnani GC, Saikia N, Banga A, Sharma SK. Non-invasive ventilation for acute exacerbation of COPD with very high $\mathrm{PaCO}(2)$ : A randomized controlled trial. Lung India 2010;27:125-30.

7. Keenan SP, Sinuff T, Cook DJ, Hill NS. Which patients with acute exacerbation of chronic obstructive pulmonary disease benefit from noninvasive positive-pressure ventilation? A systematic review of the literature. Ann Intern Med 2003;138:861-70.

8. Peter JV, Moran JL, Phillips-Hughes J, Warn D. Noninvasive ventilation in acute respiratory failure - A meta-analysis update. Crit Care Med 2002;30:555-62.

9. Lun CT, Chan VL, Leung WS, Cheung AP, Cheng SL, Tsui MS, et al. A pilot randomized study comparing two methods of non-invasive ventilation withdrawal after acute respiratory failure in chronic obstructive pulmonary disease. Respirology 2013;18:814-9.

10. Duan J, Tang X, Huang S, Jia J, Guo S. Protocol-directed versus physician-directed weaning from noninvasive ventilation: The impact 
in chronic obstructive pulmonary disease patients. J Trauma Acute Care Surg 2012;72:1271-5.

11. Damas C, Andrade C, Araújo JP, Almeida J, Bettencourt P. Weaning from non-invasive positive pressure ventilation: Experience with progressive periods of withdraw. Rev Port Pneumol 2008;14:49-53.

12. BTS/RCP London/Intensive Care Society. The use of non-invasive ventilation in the management of patients with chronic obstructive pulmonary disease admitted to hospital with acute type II respiratory failure (with particular reference to Bilevel positive pressure ventilation). www.replondon.ac.uk/sites/default/files/concise-niv-incopd-2008.pdf[Last updated on October 2008].

How to cite this article: Khilnani GC, Jain N. Do we need a protocol for weaning patients from noninvasive ventilation?. Indian J Crit Care Med 2014;18:775-7.

Source of Support: Nil, Conflict of Interest: None declared. 